\title{
POST BREXIT DYNAMICS IN EU: A POLITICAL BODY NURTURED AND RETAINED ALIVE BY THE ESP CAPILLARIES IN EDUCATION
}

\author{
Mirela Alhasani (Dubali) ${ }^{1}$, Nadežda Stojković ${ }^{2}$ \\ ${ }^{1}$ Epoka University, Tirana, Albania, ${ }^{2}$ University of Niš, Serbia
}

\begin{abstract}
Post Brexit European scenario has triggered speculative thoughts to linguists concerned with language policy in the European Union. Contrary to the belief that no Brits, no further ascendancy of English in the EU territory, there is indisputable and abundant evidence demonstrating that English will retain its status as the dominant formal and informal language among EU (and prospective) members. In our study, we argue that the sustainable and irreplaceable supremacy of English is precisely linked to its effective usage for specific purposes. We examine mainly the case of the English Medium Instruction (EMI) in higher education in EU countries shedding light on the crucial role of the ESP within EMI to further internationalization and standardization of university teaching and research within the EU zone, and its future acceding members. We also analyze indispensable role of the ESP in conducting Erasmus+ Staff and Student Mobility Exchange programs of specific majors of study as a catalyst to equal promotion and dissemination of technological and scientific innovation. We believe that the ESP is being the tool to guaranteeing economic and scientific synergy and socio-educational coherence among all EU countries.
\end{abstract}

Key words: Post Brexit English, English Medium Instruction, ESP, EU

\section{INTRODUCTION}

This study examines the status of English language in the post Brexit EU where English was left as a language without an influential official 'owner'. Unlike what some sceptics were anticipating of a decline of the English language formal and informal status in the EU, this research will argue against such sceptic attitudes through a persuasive rationale. We show that English will continue to reign. Moreover, we argue that beyond the ongoing predominance of the General English stands exactly the usage of English for Specific Purposes in the political, economic, socio-educational living processes of the EU, and as such, guarantees the multi-dimensional coherence to this political unit. We put two explicit questions to guide our analysis:

- Is there a negative impact on the status of English after UK withdrawal?

- How is English as a Medium of Instruction (EMI) making a great contribution to strong establishment of ESP in the multilingual Europe?

Submitted November $26^{\text {th }}, 2020$, accepted for publication February $2^{\text {nd }}, 2021$

Corresponding author: Nadežda Stojković. Faculty of Electronic Engineering, University of Niš, Aleksandra Medvedeva 14, 18000 Niš, Serbia |E-mail: nadezda.stojkovic@elfak.ni.ac.rs 
The first seems much of a cliché question, yet it conveys significance for our original argument. By deciphering the constant supremacy of General English (GE), we prove that it stands exactly for the ESP due to the specific flexibility and agility that ESP gives to adaptations for specific needs in the EU rather than the conservative GE mainstream. Particularly, in the multilingual zone of an artificial political sovereignty pulled to Brussels bureaucracy at quasi federal state level, the ESP communicative potential to fulfil specific needs, services and tasks is functioning as the tangible instrumental channel to connect and liaison coherently the multilingual EU. Specifically, the ESP programs are built in compatibility with the general terms of social competence as defined in the Common European Framework of Reference for Languages "social skills refer to intercultural awareness, existential competence, sociolinguistic competences, politeness conventions, register difference and functional competence" (A. Stefanowicz-Kocol \& M. Pociask, 2017).

\section{METHOD}

We utilize textual analysis as a research method aiming to describe the content, the structure, and functions of the message contained in texts. Literature shows that there are four approaches to textual analysis: rhetorical criticism, content analysis, interaction analysis, and performance studies (L. Frey, C. Botan \& G. Kresps, 1999). Specifically, we apply qualitative content analysis of texts such as the EU literature on language policy and other institutional documents; European higher education reports. This is a qualitative research in nature which, as Mason points out "qualitative research has an unrivalled capacity to constitute compelling arguments about how things work in particular contexts...is capable of producing well-founded cross- contextual generalities" (Mason, 2002). Some of the literature to be referred to in this analysis is comprised of the EU literature on language policy reports, the digital documents of universities in the European Union zone and our observations and experiences as well. Finally, we bring a comparative analysis referring to recent data findings on status of English in post Brexit EU.

\subsection{Outline}

First, we depict a chronicle of the current situation of the English language in the EU as a follow up of scholarly and political debates about the effect of Brexit onto the language policy in the EU. Then, we locate the EMI in the EU by making a point that EMI stands literally for ESP. Next, we make our analytical case that EMI implies exactly English for Specific Purposes by reaccentuating theoretical interpretations to practical illustrations. Finally, we discuss the detailed findings to highlight the prevalent dominance of the ESP in the post Brexit EU.

\section{PoST-BREXIT LINGUISTIC LANDSCAPE IN THE EU}

Most recently, English enjoys its status as an official language in the EU due to a decision taken by the Republic of Ireland guaranteeing that English would not cease to be an official language even after the British withdrawal, given that the Republic of Ireland 
was a member of the Council of Ministers of EU to vote in its favor (European Commission, 2016). However, the Guardian cites that excluding the British native speaking population, there is an increasingly growing $38 \%$ of the EU population who speaks English as a second language hence, turning it the most widely-spoken language in Europe: German takes at around 27\%, and French at nearly 24\% (Guardian, 2015). Moreover, the well-founded colonial status in Asia, and the usage of English as a lingua franca or even considered the World Englishes family, provide good motives for Europeans to communicate only in English for cross-continental communication, rather than in German or in French. Moreover, the proponents of world Englishes theory, believe that English is presented in various acceptable standards rather than a fixed British normative version. For instance, linguists acknowledge the Malaysian English, Indian English, and a multitude of other varieties being developed with their own grammars and norms. These varieties do not result because of speakers learning British English incompletely - their learning of English is aimed at an entirely different target, and English is often one of their native languages (Guardian, 2015).

Experts of translation office in the EU argue on the dramatic impact of English not to be used as a main relay language of translation for enormous documentation of the EU, if it were to be replaced by German or French. It is precisely such necessity for interpreters and translators to have English as the working language that has triggered the consolidation of a coined term for Euro-English and as accrediting the status of lingua franca to Euro-English in the near perspective (Clement, 2019).

British Council researches have concluded with very positive forecasts for the future of English in the post Brexit EU landscape conducting a needs assessment survey in seven EU countries: France, Greece, Italy, Poland, Portugal, Romania and Spain (Komorowska, 2018). Among other results, this source ascertains that English will continue to be the lingua franca in the European Union. Most importantly, employers will continue to need employees who have high level English skills, including for specific tasks, such as negotiations, solving logistical problems, or presenting a new strategy. According to interviews and data collected from feedback of top management and academic elites in these countries, it was found that adults will need 'top-up' tuition throughout their working life, as they move between different industries and roles. For instance, Barbara Baranska, head of the Polish Bank Association confirmed that "English is the number one language in the business sector" (Baranska, 2018). Similarly, Prof. Komorowska holding the position of the head of Department of Applied Linguistic at the University of the Social Sciences and Humanities in Warsaw, specified that "English is an essential skill for finding a job... There's an expectation to speak English practically in every institution, be it a chain of restaurants, or the national airport, banks" (Komorowska, 2018).

Moreover, this European survey investigated the European employers' perspectives showing the increasing demand for foreign language communication skills in the EU labor market, peaking with $69 \%$ of employers approving of English to be very significant for their organization not only at general English proficiency level but to English for industry/sector specific communication for presentations, negotiations, participation in international conference networking at events (British Council, 2018).

English has not only preserved its official language status, but it enjoys a privileged position among the three working languages of the EU and as such replacing its function in the EU could add up tremendous costs to document translation. Moreover, it has been the most used working language of diplomatic and economic negotiation language for the enlarging block members where it was used as a well-established second language of 
communication (Morgan, 2016). Philipson (2018), as a proponent of multilingual EU citizens is critical to the English hegemony. However, despite his historical-political argumentation to have constructed ongoing English hegemony, it is important for our study that he admits the supremacy of English at global and European level. He admits that there is an increasing trend in Europe to emphasize English learning to the detriment of other foreign languages, and even worse to the loss of minority language (Philipson, 2018). To sum up, it is indisputable and incontestable truth even by the opponent of the English linguistic dominance, that the position of English language is extremely wellaccommodated in the post- Brexit landscape of Europe and beyond.

\section{ENGLISH MEDIUM INSTRUCTION (EMI) IN THE EU}

Ever since the signing of Bologna Process, English language took a special status as the language of instruction of the EU and among other signatories of the Bologna Charter. English language instruction has been turned into a higher education trend for academic recognition and labor skill qualification to match the standards of European market (Munteanu, 2014). This dominance is set to grow dramatically, with $94 \%$ of secondary students in Europe learning English as a foreign language (Guardian 2015).

English language is being used as a tool for further acceleration of the internationalization process of higher education institutions precisely in the multilingual European Union landscape. Moreover, regional agencies such as the Visegrad+ have prioritized projects on improvement of English language teaching competence per tailored scientific disciplines. To illustrate, CLIL-HET project funded by Visegrad Funds, aims at grouping ESP and CLIL experts/specialists to prepare the platform for networking within V4 and Western Balkan (WB) countries to support disciplinary teachers at Higher education institutions (HEIs) to set up English education environment (EEE) (CLIL-HET, 2020). The objectives of the project were set up after a thorough needs analysis that revealed the pressure of Higher Education Institutions to provide courses taught in English to enhance students and teachers/experts mobility within EU or/and in non-EU world to share knowledge, to network and to participate in solving challenges of the current global world. Most HEIs in V4 countries provide study programs for their students in their mother tongues and what is more, in some cases ESP courses for students have been cut or completely cancelled. This might be one of the factors which lead to lower level of mobility than EU expected. To support incoming and outgoing mobility of HEIs in V4 and in WB countries (CLIL-HET, 2020).

Graddol properly anticipates the flourishing future of English language at all societal dimensions, globally and locally, such as the EU higher education usage. He argues that English is the key ingredient of the globalization and internationalization of higher education (Graddol, 2006). At global scale, he perceives English as the main driver to revolving universities from traditionally national to globally ranked for international academic recognition. In the European context, Bologna process agreed among 45 signatories, as early as in 2004 it encouraged and facilitated 1500 Master's programs offered in English even in member countries where it was not a first language (Graddol, 2006).

The current literature exhibits very motivating findings with a distinctive increase of fifty-fold times of the number of undergraduate programs taught in English in Europe. As of September 2017, there were marked more than 14.500 study programs in English instruction. France offers 322 programs at 25 universities in English language. Switzerland offers 324 programs at 15 universities (ICEF Monitor, 2017). 


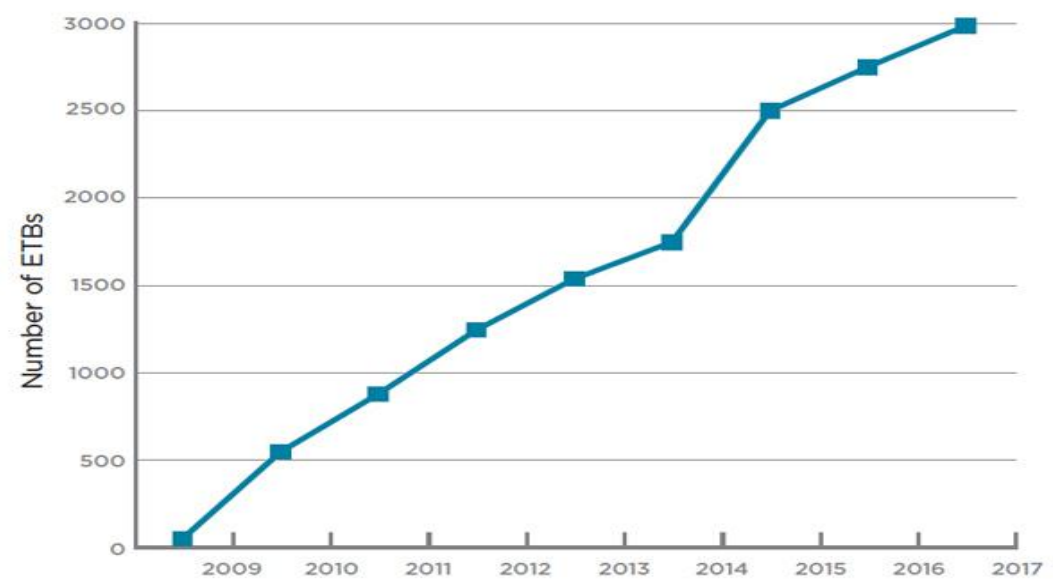

Original Source: https://monitor.icef.com/2017/09/fifty-fold-increase-english-taught-bachelorsdegrees-europe/

The above graphic shows the growing tendency of English taught degrees in nonEnglish speaking countries enhanced from 500 in 2009 to 3000 undergraduate study programs. This is a significant indicator that English programs keep becoming very popular even at bachelor's level apart from the traditionally international English taught graduate programs for international students' enrollment. Most recent statistics dating year 2020 demonstrate the ongoing upsurge in undergraduate English taught programs in most reputable European universities. For instance, The Netherlands - Leiden University, University of Amsterdam, University of Groningen. Germany - Universität Leipzig, Universität Heidelberg, Freie Universität Berlin; Sweden - Stockholm University, Lund University, Royal Institute of Technology; Denmark - The University of Southern Denmark, Aalborg University, Aarhus University; Spain - Universitat Autònoma de Barcelona, Universitat de València, Universitat Pompeu Fabra (Study Portal MASTER, 2020).

Philipson explains the upsurge of English in Europe with the ratification of the Bologna declaration. He brings in the case of Nordic countries privileging English to the same degree as their local language. The Bologna process furthers European integration but critically to him, this also intensifies the hegemony of English. Especially, the Nordic universities are moving into bilingual education, combining English with a national language. The 2006 Declaration on a Nordic Language Policy aims at ensuring that Nordic languages and English develop in parallel, that all residents can maintain their languages, and that language policy issues should be widely understood (Philipson, 2018).

\subsection{Erasmus Programs English Requirement}

Although promotion of language learning and linguistic diversity is the specific objective of the Erasmus+ Program, one of the most rewarding reasons why students invest a lot in English language mastery is to boost opportunities of intercultural and educational exchange through participation in foreign exchange program within the domain of higher education (Coleman, 2010). Joint master degrees such the International Master in Security, Intelligence and Strategic Studies is a 24 month Erasmus Mundus 
Joint Master Degree bestowed by a consortium of European Universities: University of Glasgow (UK); Dublin City University (Ireland); Charles University in Prague and the University of Trento (Italy); the University of Cadiz (Spain) and the OTH Regensburg in Germany (IMSISS, 2020). With regards to English language requirements, this consortium reconfirms the necessity to demonstrate English language competence to carry out such master studies by extending the validity period of the two renowned international English tests, TOEFL and IELTS. In addition, the vital prerequisite of consolidating high level of English proficiency is emphasized by pre-sessional English and degree level programs with standard English language requirements with the following scores:

115 - direct entry to degree programme

105 - direct entry to degree programme with compulsory in-sessional English support

100 - entry to the 5 week online Pre-Sessional English course

95 - entry to the 10 week online Pre-Sessional English course

Also, the same source, approves of English entry requirements to be equivalized by any other English degree or postgraduate studies conducted in English at the home country of the applicant (IMSISS, 2020). This current illustration of a prestigious Erasmus programs is one among thousands of Erasmus programs to prioritize the English language proficiency capabilities as the most irreplaceable requirement for entry recognition in such prestigious academic programs.

\section{ARGUMENTATIVE DISCUSSION: EMI STANDS FOR ESP}

In this part, we argue that English Medium Instruction (EMI) at the three cycles of tertiary education, all the other working tasks of the EU political institutions, and the daily communication among EU citizens, are conducted through ESP communication. One of the most renowned proponents of further English language supremacy is Marko Modiano with his remarkable scientific contribution arguing that the absence of Brits in the Union "will clear the sociolinguistic space for the emergence of an authentic European English, used by the members of the EU as a second language ... serving the needs of the European Union as the common link between language for administration and cooperation between member states" (Modiano, 2017). Modiano's argument has been early clarified and strongly advocated by Kachru in his paradigm of Inner Circles (native speaker monomodel) vis a vis the Outer Circles varieties of English (nonnative speaker polymodel) (Kachru, 1986).

Our analysis is also founded on the pillars of Kachru's paradigm and Modiano's most recent contextualization of the theory in EU's linguistic dynamics. Kachru's main argument is to reduce the stereotyping of superior white English, thus not feeling the third world English speakers inferior. Modiano's argument is that of denationalized British English being used with the status of a second language in Europe rather than a foreign language in the European context (Modiano, 2017). In his view, the original neutrality of English is likely to help it survive Brexit - and that without the UK's clout in Europe, European English will be free to do what language does best: change (Komorowska, 2018).

We defend the adjustment and survival of English through its usage as a second language rather than a foreign language for the citizens of European continent. Graddol points out the differences between English as a Foreign Language (EFL) and English as a Second Language (ESL) highlighting that in the ESP program what gains importance is the role of English in the society that is taught (Graddol, 2006, p. 84). Most interestingly, an early estimation in 2006 
embraced the argumentative thesis of Graddol that both EFL and ESL had already paved the path to a new and significant curriculum trend in Europe that of Content and Language Integrated Learning (CLIL). Contemporary research puts in the spotlight the acquisition and presentation of content in Integrating Content and Language in Higher Education (ICLHE) classes aiming to shed light on the importance of learning content in the ICLHE settings (Francesca Costa \& Cristina Marioti, 2017). English language training is perceived essential to persistent professional development of international classroom lecturers. Academic staff are expected to deliver insights on the institutional policies and strategies for internationalization of the institution's programs of the study environment. It has been ascertained that given the expanded definition of internationalization of universities in Europe, lecturers, curriculum designers and mentors need to collaborate on a long-term systematic approach instead of the ad hoc activities (Lauridsen, 2017).

In other words, English nowadays is being taught and used for functional purposes unlike the classic goal to prepare would-be-linguists or would-be-teachers of English. EU dynamics is going through the same needs and evolvements of the world in the 1960. The latter was a moment where ESP came into existence imposed by the identified linguistic needs for tailored English communication for occupational and specific activities (Strevens, 1988). Needs analysis also referred to as needs assessment has been defined by Basturkmen as "the identification of difficulties and standard situations by observation of participants functioning in a target situation in conjunction with interviews and questionnaires" (Basturkmen, 2008). It is precisely the needs analysis the main distinctive pillar of the ESP courses as compared to standard ELT (John, Tonny Duddley-Evans \& M. St., 1998)

Similarly, we argue that the contemporary reasons why adult European citizens use and need English for real professional and educational targets, provides enough data on the curriculum shift from GE to ESP after such a needs assessment by the EU citizens itself. The Institute of Research Studies about the Anglophone World (Laboratoire d'Etudes et de Recherche sur le Monde Anglophone), reports that there is a growing demand for training in English for non-English leaners triggered by the globalization processes. It argues that the generalization of English language teaching in all professional and academic domains has been increasing the demand for skilled ESP practitioners having very few on offer (Yeught, 2016). This significant finding certifies connivingly the constant need for ESP courses and training and, therefore, it rejects any skepticism about further official and functional usage of English in the EU policy.

\section{CONCLUSION}

This article examined the linguistic landscape of the post-Brexit EU arguing the ongoing supremacy of the use of English language within it. It was not limited to solely casual roots location of further English language reign among the other EU official languages. Instead, it also argued that English will continue its dominance due to its adjustment and reformation from general English mainstream into English for Specific Purposes mainly in the framework of an extremely expanding English Medium Instruction in the multilingual Europe. The literature from EU institutions provided vast statistical evidence on the augmenting number of English taught programs in the EU zone. Moreover, it proved the growing need for functional tailored communication to perform disciplinary programs in English, as well as the need to perform informal and formal political, economic, and cultural 
activities though English language coined as EURO English having gained a very original linguistic identity of its own. We demonstrated that it is precisely such new globalization and integration needs for efficient and relevant communication that explain not only the immunity of English language from the Brits speakers, but it made the point of the safe and consolidated status of English language as a link to unite the multilingual union rather than drif it apart. We believe that further research in the ESP needs analysis and practical cases of accomplishments within EU will reinforce this finding of the general English communication being replaced by the need for ESP communication as the sole linguistic channel to guarantee a united EU. The forthcoming contributions of the new member states to join the plurilingual EU, and their resolution to offer high quality EMI through reformation of the ESP courses, will shed more light onto future evolutionary processes of the ESP track in the EU.

\section{REFERENCES}

A. Stefanowicz-Kocol \& M.Pociask. (2017). Improving Social Competence for Nursing Students in ESP Classes. THe Journal of Teahcing English for Specific and Academic Purposes, 261.

Baranska, B. (2018, October). The Future Demand for English in Europe: 2025 and beyond. British Council. Retrieved from British Council: https://www.britishcouncil. org/sites/default/files/future_demand_for_english_in_europe_2025_and_beyond_briti sh_council_2018.pdf

Basturkmen, $\bar{H}$. (2008). Ideas and Options in ENglish for Specific Purposes. (pp. 2-5). Taylor and Francis.

British Council . (2018). The future demand for English in Europe: 2025 and beyond. British Council. Retrieved from https://www.britishcouncil.org/sites/default/files/ future_demand_for_english_in_europe_2025_and_beyond_british_council_2018.pdf

British Council . (2018). The future demand for ENglsih in Europe: 2025 and beyond. British Council. Retrieved from https:/www.britishcouncil.org/sites/default/files/ future_demand_for_english_in_europe_2025_and_beyond_british_council_2018.pdf

Clement, A. (2019, September 8). University of Strasbourg. Retrieved from What future for English in the EU after BREXIT?: https://mastertcloc.unistra.fr/2019/09/08/ english-in-the-eu-after-brexit/

CLIL-HET. (2020). Retrieved from https://clil-het.eu/project-corner/

Coleman, H. (2010). The English Language Development. British Council . Retrieved from https://www.teachingenglish.org.uk/sites/teacheng/files/UK011-English-LanguageDevelopment.pdf

European Commission. (2016). Retrieved from ec.europa.eu/ireland/news/statemnet-onbehalf-of-the European-Commission-Representation_en

Francesca Costa \&Cristina Marioti. (2017). Differences in content presentation and learning outcoms in English-medium instruction (EMI0 vs. Italian -medium instruction (IMI) contexts. In J. Valcke, \& R. Wilkinson., Integrating Content and Language in Higher Education: Perspectives on Professional Practice. Frankfurt am Main: Peter Lang Edition.

Graddol, D. (2006). Eglish Next. British Council. 
Guardian, T. (2015). ICYMI, English language is changing faster than ever, says expert. Retrieved from https://www.theguardian.com/science/2015/may/01/icymi-englishlanguage-is-changing-faster-than-ever-says-expert

ICEF Monitor. (2017). Retrieved from https://monitor.icef.com/2017/09/fifty-foldincrease-english-taught-bachelors-degrees-europe/

IMSISS. (2020, May). Update on English language requirements fro 2020 entry. Retrieved from http://securityintelligence-erasmusmundus.eu/update-on-englishlanguage-requirements-for-2020-entry/

John, Tonny Duddley-Evans \& M. St. (1998). Developments in English for Specific Purposes: A multidisciplinary Approach. Cambridge University Press.

Kachru, B. (1986). The alchemy of English: the spread, functions, and models in nonnative English. Oxford: Oxford University Press.

Komorowska, H. (2018, October). EU 2025: The future demand for English language in the European Union. Retrieved from British Council: https://www.britishcouncil. org/sites/default/files/future_demand_for_english_in_europe_2025_and_beyond_briti sh_council_2018.pdf

L. Frey, C. Botan \& G. Kresps. (1999). Investigating communication: An introduction to research methods. Boston: Allyn \& Bacon.

Lauridsen, K. M. (2017). Professional Devleopment of International classroom lecturers. In J. V. (eds), ntegrating Content and Language in Higher Education: Perspectives on Professional Practice (pp. 25-37). Frankfurt am Aim : Peter Lang.

Mason, J. (2002). Qualitative Research (2nd ed.). London: Sage Publications.

Modiano, M. (2017). English in a post-Brexit European Union. World Englishes, 319.

Modiano, M. (2017). English in a post-Brexit European Union. World Englishes, 313-314.

Morgan, S. (2016). Brexit and English Language Teaching. Retrieved from https://www.etprofessional.com/brexit-and-english-language-teaching

Munteanu, S. (2014). English Medium Instruction in European Higher Education Institutions: how do the objectives and outcomes compare with the situation wolrdwide? English for SPecific Purposes World, 15(44), 1-3. Retrieved from www.esp-world.info

Nunnan, D. (2013). Learner-Centered English Language Education (1 ${ }^{\text {st }}$ Edition ed.). Routledge, Taylor and Francis Group.

Philipson, R. (2018). Language Challenges in Global and Regional Integration. Sustainable Multlingualism(12), 14-17. doi:https://doi.org/10.2478/sm-2018-0001

Strevens, P. (1988). ESP: State of the Art. In M. T. eds, ESP after 20 years: A reappraisal (pp. 1-13). Singapore : SEAMEO.

Study Portal MASTER. (2020). Retrieved from Non English European countries with most English-taught degrees : https://www.mastersportal.com/articles/1717/nonenglish-european-countries-with-most-english-taught-degrees.html

Tom Hutchinson \& Alan Waters. ( 1987). English For Specific Purposes. Cambridge University Press.

Yeught, M. v. (2016). Developing English for Specific Purposes in Europe: mainstream approaches and complementary advances. 13th ESSE Conference. University de Galway Ireland. 